\title{
Genetic authentication of Eclipta prostrate (Asteraceae) from Penthorum chinense (Penthoraceae) by Sequence Characterized Amplified Region (SCAR) markers
}

\author{
Zhiqiang $\mathrm{Mei}^{1}$, Md. Asaduzzaman $\mathrm{Khan}^{1}$ \& Junjiang $\mathrm{Fu}^{2 *}$ \\ 1. The Research Center for Preclinical Medicine, Southwest Medical University, Luzhou, Sichuan 646000, China; \\ xuguangyin1@163.com, asadkhanbmj@yahoo.com \\ 2. Key Laboratory of Epigenetics and Oncology, The Research Center for Preclinical Medicine, Southwest Medical \\ University, Zhongshan Road, Luzhou, Sichuan 646000, China; fujunjiang@swmu.edu.cn, fujunjiang@hotmail.com \\ * Correspondance
}

Received 28-IV-2019. Corrected 14-XI-2019. Accepted 20-I-2020.

\begin{abstract}
Introduction: For the rapid and accurate genetic identification and authentication of living organisms, improved random amplified polymorphic DNA (RAPD) fragment based development of sequence-characterized amplified region (SCAR) markers is an important genetic technique. Objective: This study aimed to develop SCAR markers for perennial herb Eclipta prostrate (E. prostrate). Methods: Here the RAPD fragments by improved RAPD amplification with primers A11 and N-7 for E. prostrate were cloned into pGEX-T vector, and PCR amplification identified the positive clones. After the enzymatic digestion, they were sequenced with Sanger sequencing. Results: Two SCAR markers were developed, which were very specific to E. prostrate, not found in Penthorum chinense Pursh ( $P$. chinense). The nucleotide sequence search by BLAST GenBank database showed that they are novel in E. prostrate, therefore they were deposited in Genbank with accession number KX671034, KX671035. The markers did not show any identity to other species. Conclusions: Thus, in this study two specific SCAR markers were developed for genetically distinguishing and identifying the plant species E. prostrate from herb P. chinense and others.
\end{abstract}

Key words: Eclipta prostrate; genetic authentication; Penthorum chinense Pursh; random amplified polymorphic DNA; sequence characterized amplified region.

Mei, Z., Khan, M.A., \& Fu, J. (2020). Genetic authentication of Eclipta prostrate (Asteraceae) from Penthorum chinense (Penthoraceae) by Sequence Characterized Amplified Region (SCAR) markers. Revista de Biología Tropical, 68(1), 180-188.

The traditional Chinese medicinal (TCM) plant Eclipta prostrate, commonly known as False Daisy (lǐ cháng in Chinese), is widely distributed throughout India, Nepal, China, Thailand, and Brazil. In Oriental regions, E. prostrate has medicinal usage, mainly as purgative, and external usage for skin diseases. Moreover, the decoction of E. prostrate leaves is used for normal hair-growth of new born babies in India. Research studies showed that extracts from $E$. prostrate can protect normal human bronchial epithelial (NHBE) cells from cigarette smoke extracts (CSE) (Ding et al., 2014); a natural compound $\alpha$-terthienylmethanol from E. prostrate can induce apoptosis in human endometrial cancer cells by ROS production via NADPH oxidase (Lee et al., 2015). Recently, another natural compound Wedelolactone, isolated from E. prostrate, exhibited prevention of vascular remodeling and neointimal hyperplasia by VSMC proliferation through Akt inhibition and AMPK activation (Peng et al., 2017). The recent interests of medicinal chemists in this plant have influence on the identification system of this plant species, and their genetic authentication from other highly 
morphological similar substitutes, such as Penthorum chinense Pursh (P. chinense) with different medicinal properties and activities.

P. chinense, also known as 'Gan huang cao', is a perennial herb with a rich history of medicinal use in different parts of China, especially among Miao ethnic group (Mei et al., 2017a; Mei, Khan, Zhang, \& Fu, 2017b). P. chinense is mainly found in East Asian regions like China, Korea, Thailand, Vietnam, Laos, Mongolia as well as some parts of Russia, and in China it is found as wild-borne in several parts including Guizhou Hunan, Jiangxi, Sichuan (Flora of China, 2017). P. chinense is useful against certain diseases like liver damage, chronic liver injury and hepatitis. Reports indicate it possess antioxidant and anticancer properties, as well as being hepatoprotective, antiviral and antidiabetic (Cao et al., 2015; Feng, Wang, Dong, \& Wu, 2001; Hu et al., 2015; Huang et al., 2015; Lu, Jiang, Jiang, Zhang, \& Zhang, 2012; Wang, Liu, \& Feng, 2006; Wang et al., 2014; Wang, Lin, \& Wang, 2015; Wang et al., 2017; Zhang, Xu, Jiang, \& Jiang, 2013).

In recent biotechnological era, different types of molecular bio-techniques have been applied for genetic identification and authentication of different plants, animals and bacteria. For example, AFLP (amplified fragment length polymorphism), ISSR (inter-simple sequence repeat), RAPD (random amplified polymorphic DNA), SSR (simple sequence repeat), SCAR (sequence characterized amplified region),
STR (short tandem repeat) etc. (Williams, Kubelik, Livak, Rafalski, \& Tingey, 1990; Fu, Yang, Khan, \& Mei, 2013; Khan, Cheng, Mei, Wei, \& Fu, 2016; Mei, Zhang, Liu, Imani, $\& \mathrm{Fu}, 2017 \mathrm{c}$; Fu et al., 2018). A combination of RAPD and SCAR marker analysis or SCAR marker alone provides a high level of authenticity of genetic identification (Fu et al., 2015; Fu et al., 2017). Molecular analysis has been simplified in a PCR reaction using PCR primers designed based on RAPD amplicons in SCAR marker technique (Kumla, Doolgindachbaporn, Sudmoon, \& Sattayasai, 2012; Fu et al., 2015). However, the genetic relationships between $P$. chinense and $E$. prostrate have not been studied yet and there is no report on SCAR marker development from E. prostrate; however, we developed $P$. chinensee-specific SCAR markers previously (Mei et al., 2017a).

Here in this study, the SCAR markers specific to E. prostrate were developed, which can genetically identify and distinguish the medicinal plant $E$. prostrate from closely related herbal $P$. chinense Pursh, as well as other organisms.

\section{MATERIALS AND METHODS}

DNA Extraction: A total of nine Penthorum chinense Pursh accessions from different regions of China and one Eclipta prostrate was described previously in Table 1 (Mei et al., 2017a). Other samples, Eclipta prostrate,

TABLE 1

Sources of RAPD samples

\begin{tabular}{cllc} 
No. & \multicolumn{1}{c}{ Name } & \multicolumn{1}{c}{ Sources } & Sample \\
1 & Penthorum chinense Pursh & Yingtan, Jiangxi & YT \\
2 & Penthorum chinense Pursh & Anqing, Anhui & AQ \\
3 & Penthorum chinense Pursh & Ankang,Shanxi & AK \\
4 & Penthorum chinense Pursh & Chenzhou, Hunan & CZ \\
5 & Penthorum chinense Pursh & Luzhou, Sichuan & LZ \\
6 & Penthorum chinense Pursh & Xichang, Sichuan & XC \\
7 & Penthorum chinense Pursh & Zunyi,Guizhou & ZY \\
8 & Penthorum chinense Pursh & Yichang,Hubei & YC \\
9 & Penthorum chinense Pursh & Xinzhou,Shanxi & XZ \\
10 & Eclipta prostrate & Luzhou, Sichuan & LZ \\
\hline
\end{tabular}


Canarium album (Lour.) Raeusch, Dimocarpus longan Lour., Litchi chinensis Sonn., Mentha haplocalyx Briq., Lycium barbarumL., Angelica sinensis (Oliv.) Diels, Ginkgo biloba L., Herba Acroptili Repentis, Ganoderma lucidium (Leyss.ex Fr.) Karst. , Ganoderma japonpcum, Gardenia jasminoides Ellis, Artemisia argyi H. Lév. and Vaniot, were also collected from different parts of China. Genomic DNA was isolated from fresh leaves of the collected plants by using modified Cetyl Trimethyl Ammonium Bromide (CTAB) method, and the DNA quality was checked by agarose gel electrophoresis $(0.8 \%)$ and spectrophotometry $(\mathrm{Fu}$, 2012; Fu et al., 2013). The plants were carefully identified and the specimens have been deposited at the source bank of the Southwest Medical University.

Improved RAPD Amplification: Different DNA samples were used for PCR amplification with RAPD primers A11, and N7. The PCR reaction system of $10 \mu \mathrm{l}$ was consisted of $1.5 \mu \mathrm{l}$ genomic DNA, $5 \mu \mathrm{l} 2 \times$ Taq PCR Mas-

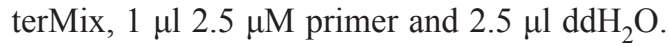
Applied Biosystems Veriti ${ }^{\circledR}$ 96-Well Thermal Cycler (Life Technology, USA) was used for PCR amplification, and the steps were as follows: (1) $90 \mathrm{~s}$ at denaturation at $95^{\circ} \mathrm{C}$ for $90 \mathrm{~s}$, (2) 40 cycles of denaturation at $94{ }^{\circ} \mathrm{C}$ for $40 \mathrm{~s}$, annealing at $36{ }^{\circ} \mathrm{C}$ with the RAMP rate from annealing to extension adjusted to $0.125^{\circ} \mathrm{C} / \mathrm{s}$ (5\% ramp rate) for $60 \mathrm{~s}$, extension at $72{ }^{\circ} \mathrm{C}$ for $90 \mathrm{~s}$, and (3) a final extension step at $72{ }^{\circ} \mathrm{C}$ for 5 min (Mei et al. 2015a, 2017).

Electrophoresis by agarose gel: PCR products for RAPD amplification were loaded for electrophoresis into agarose gel $(1.5 \%)$. The amplified PCR products for developing SCAR markers were separated into $1.8 \%$ agarose gel. Ethidium bromide (EtBr) staining was used for visualizing the gels and the images were captured in Chemi Doc XRS system (BioRad, USA) (Fu, 2012).

Molecular cloning: The bright bands in agarose gel were cut and purified (with
TIANgel Mini DNA Purification Kit (DP209, Tiangen reagents, Beijing, China). The vector pGM-T (No. VT202) (purchased Tiangen reagents, Beijing, China) was sued for AT cloning and the purified DNA fragments were ligated. Then they were transformed into $\mathrm{DH} 5 \alpha$ E. coli competent cells, and spread on LB agar plates containing ampicillin $(100 \mu \mathrm{g} / \mu \mathrm{l}), \mathrm{X}$-gal $(40 \mathrm{mg})$ and IPTG $(160 \mu \mathrm{g})$. The plates were then incubated at $37^{\circ} \mathrm{C}$ for overnight, and the white colonies were screened out by blue white screening. The correct insert was confirmed by PCR, where T7/SP6 primer pairs were used. The colony PCR condition was as follows: (1) initial denaturation at $95{ }^{\circ} \mathrm{C}$ for $90 \mathrm{~s}$, then (2) 35 cycles of denaturation at $94{ }^{\circ} \mathrm{C}$ for $40 \mathrm{~s}$, annealing at $60{ }^{\circ} \mathrm{C}$ for $30 \mathrm{~s}$, extension at $72{ }^{\circ} \mathrm{C}$ for $90 \mathrm{~s}$, and (3) a final extension step at $72{ }^{\circ} \mathrm{C}$ for 5 min, with "Applied Biosystems Veriti ${ }^{\circledR}$ 96-Well Thermal Cycler”. PCR products were then run on $1.5 \%$ agarose gel for electrophoresis (Mei et al., 2015a; Khan et al., 2016; Fu et al., 2017).

DNA sequencing and bioinformatics: The positive clones N7-11 (clone 1) and A1121 (clone 1) were performed sequencing by Sanger method using SP6 of T-vector primer. The homology of sequenced DNA clone was searched in BLAST (online program; available in http://www.ncbi.nlm.nih.gov/BLAST/) in GenBank database to verify the novelty of cloned fragments.

SCAR primer design: Primer 3 (http:// bioinfo.ut.ee/primer3-0.4.0/primer3/) was used for designing primer pairs for SCAR based on the sequence of RAPD fragments (Cheng et al., 2019). The quality of each pair primers was tested to optimized amplification condition. Primer sequence, optimum PCR condition and PCR product length are presented in Table 2.

Species-specific SCAR marker development: For developing the stable SCAR markers, the PCR was performed with 22 DNA samples. The content of $10 \mu \mathrm{l}$ PCR reaction was as follows: $5 \mu \mathrm{l} 2 \times$ Taq PCR MasterMix, 
TABLE 2

Sequences of SCAR primers, PCR product size and PCR condition

\begin{tabular}{ccccccc} 
SCAR & 5'-primer & Sequence $\left(5^{\prime}-3^{\prime}\right)$ & 3'-primer & Sequence $\left(5^{\prime}-3^{\prime}\right)$ & Size $(\mathrm{bp})$ & $\mathrm{Tm}\left({ }^{\circ} \mathrm{C}\right)$ \\
A11-21 & A11-21L & ATCGATTCCCGGTCCTACAG & A11-21R & TGGGTATTCTTCTTAGCAACCAA & 249 & 64 \\
N7-11 & N7-11L & AGAAAATGCAAACCGGAGGT & N7-11R & CGTTGACTCCCACACATCCT & 214 & 64 \\
\hline
\end{tabular}

$1 \mu \mathrm{l}$ of $2.5 \mu \mathrm{M}$ each pair of SCAR primers, and $1 \mu \mathrm{l}(10 \mathrm{ng})$ genomic DNA, $3 \mu \mathrm{l}$ of $\mathrm{dd}_{2} \mathrm{O}$. $\mathrm{PCR}$ reaction was performed in a thermal cycle (mentioned above) with the following steps: (1) an initial pre-denaturation for $90 \mathrm{~s}$ at $95^{\circ} \mathrm{C}$, (2) followed by 29 cycles of denaturation at $94{ }^{\circ} \mathrm{C}$ for $40 \mathrm{~s}$, annealing at $64^{\circ} \mathrm{C}$ for $30 \mathrm{~s}$, and extension at $72{ }^{\circ} \mathrm{C}$ for $40 \mathrm{~s}$, and finally (3) extension at $72{ }^{\circ} \mathrm{C}$ for $5 \mathrm{~min}$.

\section{RESULTS}

Molecular cloning of fragments generated by RAPD amplification: Results shown in Fig. 1, indicate the bands with specific primers (the white arrows). These bands were cut from the gel, and DNA was purified. A11 and N7 RAPD primers were used for the improved RAPD amplification of DNA sample Eclipta prostrate. After the PCR, ligation, the white clones were screened by PCR with SP6/T7 primer pair, and the results of colony PCR are shown in Fig. 2A. In Fig. 2A, the positive clones from fragments N7-11 showed in lane 1 and 2, and positive clones from fragments A1121 showed in lane 3 and 4, all with expected

A

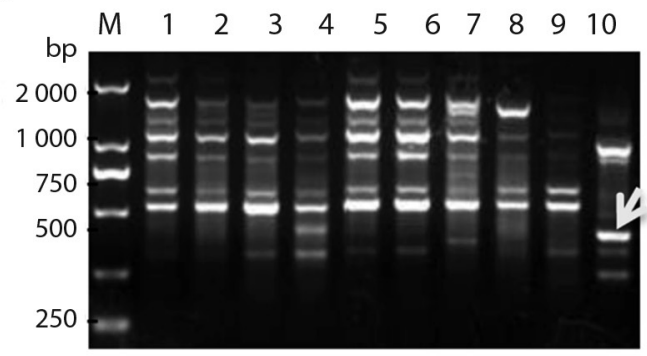

Primer A11 amplified DNA-fragment sizes, whereas in Fig. 2B, both A11-21 and N7-11 also showed expected inserted fragments in lane 2 and 4 with EcoR I digestion.

Characterization of specific fragments generated by RAPD: After the RAPD fragment clones A11-21 and N7-11 were sequenced by Sanger method, the BLAST searches indicated that the fragments were not significantly identical to any other species. Clone A11-21 consisting of 363 nucleotides, and clone N7-11 consisting of 462 were deposited into GenBank with accession number KX671034 and KX671035, respectively (Fig. 3A, Fig. 3B) Notably, the actual lengths with high quality nucleotide we obtained are shorter than that of the colony PCR or EcoR I digestion.

Development of specific SCAR markers and authentication of $E$. prostrate from other species: To generate stable $E$. prostratespecific diagnostic SCAR markers, two primers pairs were designed, and synthesized based on RAPD-dependent cloned fragments (Table 2 ), which were then used for PCR amplification

\section{B}

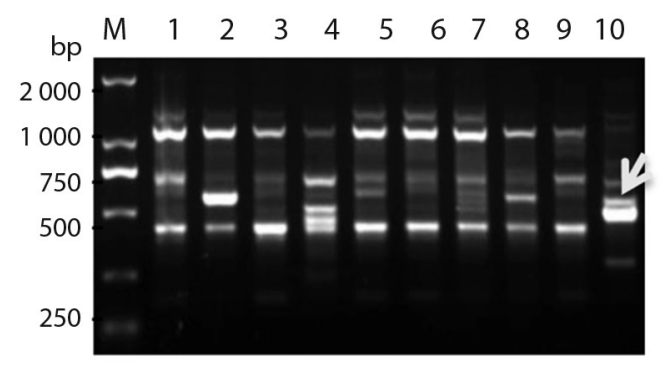

Primer N7

Fig. 1. Improved RAPD amplification. RAPD amplification from DNA samples from $P$. chinense and E. prostrate using different RAPD primers A. A11 and B. N7 (B). The arrows pointed PCR fragments were cut from gels for further cloning. 
A

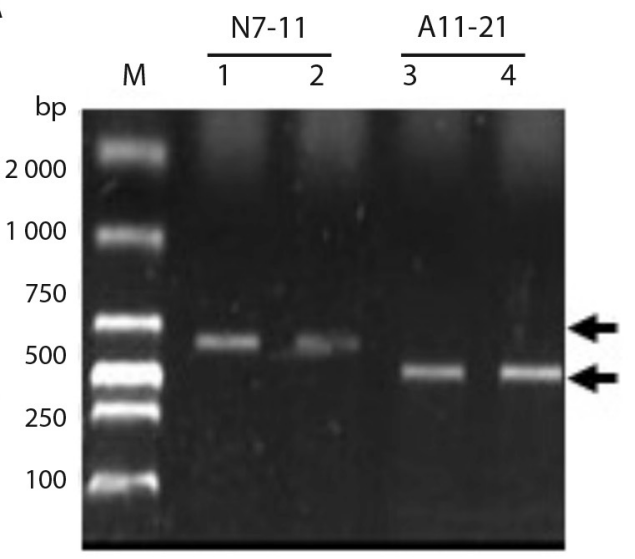

B

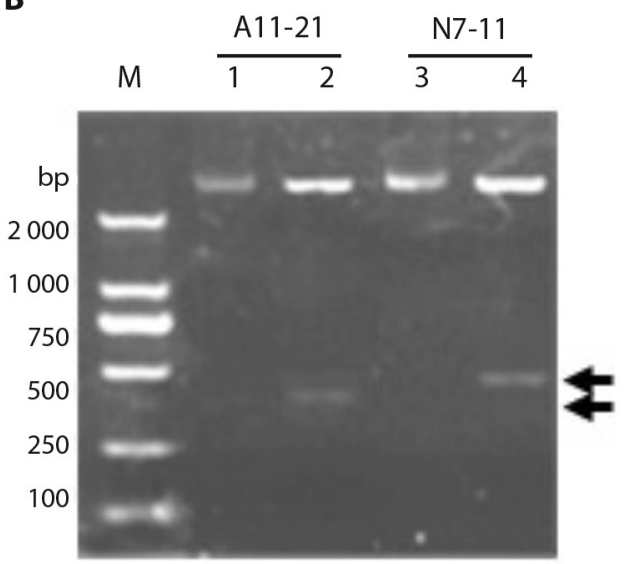

Fig. 2. Identification of positive clones after DNA ligation by colony PCR and enzymatic digestion from E. prostrate. A. Clone identification of RAPD fragments N7-11 (two clones 1,2) and A11-21 (two clones 1 and 2). Both clones 1 in blue are selected for enzymatic digestion and Sanger sequencing. B. Clone identification of clones N7-11 (1) and A11-21 (1) by without (lanes 1,3) or with (lanes 2,4) EcoRI digestion. The black arrows represent desired PCR product or specific insert bands in different clones.

A

1 ATCGCCGTCAAATAGGATTCCGCACTATTTGATAGGTTTAGGTGTTAAATTCGATAGGAATCATCGATTCCCGGTCCTAC

81 AGTCCTGTTCTTTCTTTCAGCTATACCATTTTGTTGTGGAGTGTATGGTGAACTGTATTGCCGAGTGATCCCCTTTTTGT

161 CACAAAAATCAGTTAATTCAAAATTCTTGAACTCTGTACCATTATCACATCTGATTATCTTCACCTTCTCATTTAACAAA

241 TTTTCTAATTTTAAAATCAGATGTTGTACATAGGTAACTGTTTCAGATTTGGTTGCTAAGAAGAATACCCAACTGTATCT

321 TGAGATTTCATCAGTGACAACAAGACAATAGGATTTTCGACCT

B

1 TTTACAAAAGAGAATTCTTGTTCTTTTTTTCGTCAAAACTGAAATTCTTTAATATTATGTTTTGCTCTTTGTTCTCATTT

81 CCAGCTTTATGGAGAAAATGCAAACCGGAGGTGATCTTAACCTCATCGGTCAGTTTGGTGTTGGATTTTATTCTGTATAT

161 CTTGTTGCTGATTATGTGGAAGTGATAAGCAAACACAATGATGACAAACAGTATGCCTTCTGGTTTTTGTTCTGCAGTAG

241 TCGATTTTAGCTTTACTTATCAACTTGCTTCAACTTGTAACTTTTTAGGATGTGTGGGAGTCAACGGCTGATGCCGCATT

321 TGCGACTCTGAAGATACATACAATGAGCCACTCGGTCATGGTACTGAAATAAGATTGCATCTTAGGAACGAAGCCGGAGA

401 ATATCTTGAAGAGTCAAAATTGAAGGATTTGGTGAAAAAATATTCGGAATTTATTAACTTCC

Fig. 3. Sequencing result of the cloned nucleotides. A. The sequences of clone A11-21 with $363 \mathrm{bp}$. The GenBank accession number: KX671034; B. The sequences of clone N7-11 with 462 bp. The GenBank accession number: KX671035.

of DNA materials collected from 22 samples of different species or cultivars for verifying species-specificity. As shown in Fig. 4, the PCR results indicated that the amplification products of A11-21, N7-11 with expected size were observed in sample $E$. prostrate only (Fig. 4A, Fig. 4B; lane 10); no amplification in other species, including $P$. chinense, demonstrating that the highly specific SCAR markers were successfully developed. Therefore, these SCAR markers A11-21, N7-11 can be used for the authentication of this medicinal plant from $P$. chinense and other species or cultivars. The two SCAR markers specific to E. prostrate, developed in this study are deposited in Genbank with accession no. KX671034 and KX671035.

\section{DISCUSSION}

Genetic characterization and identification of numerous living organisms have been 
A

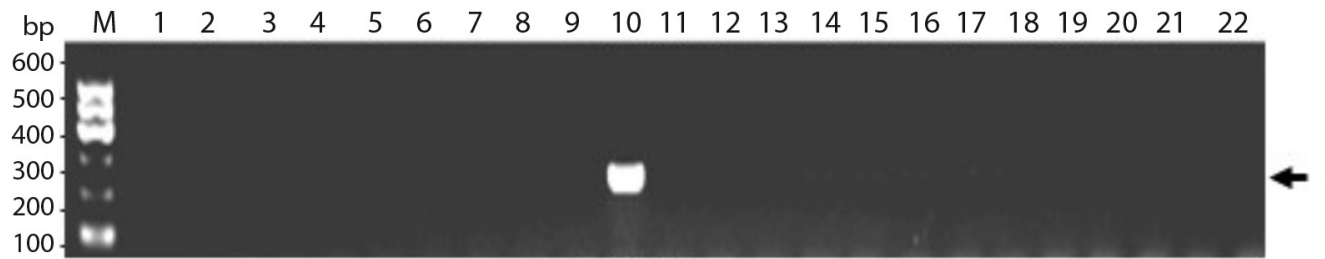

A11-21

B

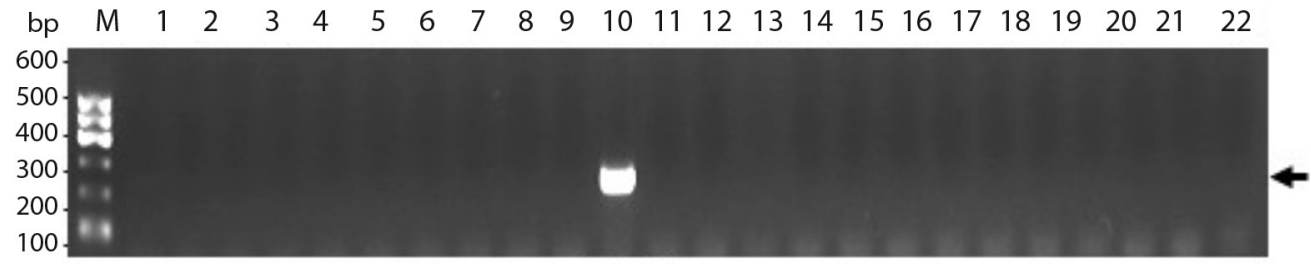

N7-11

Fig. 4. Stable RAPD-SCAR marker development for A. A11-21 and B. N7-11. Lanes 1-9 are Penthorum chinense Purshes, lane 10 is Eclipta prostrate, lanes 11-22 are Canarium album (Lour.) Raeusch, Dimocarpus longan Lour., Litchi chinensis Sonn., Mentha haplocalyx Briq., Lycium barbarum L., Angelica sinensis (Oliv.) Diels, Ginkgo biloba L., Herba acroptili Repentis, Ganoderma lucidium (Leyss.ex Fr.) Karst. Ganoderma japonpcum, Gardenia jasminoides Ellis, Artemisia argyi H. Lév. \& Vaniot.

revolutionized by the development of genetic markers (Mei et al, 2017). These techniques have become very useful tools for the system biologists, botanists, zoologists, and even for the medicinal chemist. Most of these marker techniques are simple, cheap, easy to handle, and sequencing of DNA is unnecessary, but they were revealed high degrees of polymorphisms (Williams et al., 1990, Fu et al., 2013, 2015). Combination of RAPD with SCAR can improve the stability and specificity, and makes the process of genetic analysis more effective in studying different species (Mei et al., 2017b). Our lab and other groups, have successfully characterized a number of plant or fungal species by developing SCAR markers based on RAPD amplicons, such as, Dimocarpus longan (Yang, Fu, Khan, Zeng, \& Fu, 2013), Acorus species (Ryuk, Kim, Lee, \& Ko, 2014), Lonicera japonica (Yang et al., 2014), Trichoderma cf. harzianum (Pérez, Verdejo, GondimPorto, Orlando, \& Carú, 2014), Cordyceps sinensis (Lam et al., 2015), Litchi chinensis (Cheng et al., 2015), Angelica sinensis (Zhang et al., 2015), Gardenia jasminoides Ellis var. grandiflora Nakai (Mei et al., 2015b), Ganoderma Lucidum (Khan et al., 2016), Penthorum chinense Pursh (Mei et al., 2017b), as well as developing diagnostic SCAR markers from female breast carcinomas (Fu et al., 2017).

$E$. prostrate is often confused with $P$. chinense for their phenotypes, but they are genetically different, which is confirmed by our present study. In this study, we have generated RAPD fragments by using DNA materials extracted from these plants and cloned into T-vectors by collecting E. prostrate and $P$. chinense species in China. Successfully, we developed two SCAR markers A11-21, N7-11, which are strictly specific to the sample of $E$. prostrate; not $P$. chinense. Thus these markers can be used for the genetic analysis, and to identify and authenticate $E$. prostrate from P. chinense species or other species. As the BLAST searches in GenBank database did not show similarity with these two nucleotide sequences (KX671034, KX671035), these SCAR fragments are novel molecular markers for E. prostrate species. As far we know, this is 
the first time to develop E. prostrate-specific SACR markers.

These E. prostrate-specific SACR markers, A11-21, N7-11, can be used for the genetic identification and authentication of this plant from $P$. chinense and other species or cultivars. Establishment of these SCAR markers will provide easier ways to authentically identify $E$. prostrate species, and contribute in the biological distinguish of this plant from $P$. chinense. More scientific studies can be performed to identify genomic information and isolate the active ingredients from this $E$. prostrate plant to investigate their medicinal properties.

Ethical statement: authors declare that they all agree with this publication and made significant contributions; that there is no conflict of interest of any kind; and that we followed all pertinent ethical and legal procedures and requirements. All financial sources are fully and clearly stated in the acknowledgements section. A signed document has been filed in the journal archives.

\section{ACKNOWLEDGMENTS}

The work was supported by the Joint Research Foundation of Luzhou City and Southwest Medical University (2018LZXNYD YL01), the Joint Program of the Science \& Technology of Luzhou and the Science \& Technology Department of Sichuan (14JC0154), The Sichuan Provincial Health Department (130279) and Scientific Research Fund of Sichuan Provincial Education Department (14ZA0152, 17ZA0427), and in part by the National Natural Science Foundation of China (30371493).

\section{RESUMEN}

\footnotetext{
Autenticación genética de Penthorum chinense (Penthoraceae) en Penthorum chinense (Penthoraceae) con la técnica "SCAR". Introducción: Verificación genética del arbusto Eclipta prostrate (Asteraceae) (Para la identificación y verificación genética rápida y precisa de organismos vivos, el uso de fragmentos de ADN polimórfico amplificado aleatoriamente (RAPD) mejorado
}

de marcadores de región amplificada caracterizada por secuencia (SCAR) es una técnica genética importante. Objetivo: Este estudio tuvo como objetivo desarrollar marcadores SCAR para la hierba perenne Eclipta postrate (E. postrate). Métodos: En este estudio os fragmentos RAPD mediante amplificación RAPD mejorada con los cebadores A11 y N-7 para E. postrate se clonaron en el vector pGEX-T, y la amplificación por PCR identificó los clones positivos. Después de la digestión enzimática, se realizó una secuenciación Sanger. Resultados: se desarrollaron dos marcadores SCAR, muy específicos para E. postrate, que no se encuentran en Penthorum chinense Pursh $(P$. chinense). La búsqueda de las secuencias de nucleótidos con BLAST en GenBank mostró que son nuevos en $E$. postrate, por lo que fueron depositados en Genbank con los números de acceso: KX671034 y KX671035. Los marcadores no mostraron ninguna identidad a otras especies. Conclusiones: En este estudio se desarrollaron dos marcadores SCAR específicos para distinguir e identificar genéticamente la especie de planta E. postrate de la hierba $P$. chinense y otras.

Key words: Eclipta prostrate, auntentificación genética, Penthorum chinense Pursh, ADN polimórfico amplificado aleatoriamente, región amplificada caracterizada por secuencia.

\section{REFERENCES}

Cao, Y. W., Jiang, Y., Zhang, D. Y., Wang, M., Chen, W. S., Su, H., Wang, Y. T., \& Wan, J. B. (2015). Protective effects of Penthorum chinense Pursh against chronic ethanol-induced liver injury in mice. Journal of Ethnopharmacology, 161(1), 92-98. DOI: 10.1016/j. jep.2014.12.013.

Cheng, J., Fu, J., Zhou, Q., Xiang, X., Wei, C., Yang, L., Fu, S., Khan, M. A., Lv, H., \& Fu, J. (2019). A novel splicing mutation in the PRPH2 gene causes autosomal dominant retinitis pigmentosa in a Chinese pedigree. Journal of Cellular and Molecular Medicine, 23(5), 3776-3780. DOI: 10.1111/jcmm.14278.

Cheng, J., Long, Y., Khan, M. A., Wei, C., Fu, S., \& Fu, J. (2015). Development and significance of RAPDSCAR markers for Litchi chinensis Sonn. variety authentication by improved RAPD amplification and molecular cloning. Electronic Journal of Biotechnology, 18(1), 35-39. DOI: 10.1016/j.ejbt.2014.11.004

Ding, S. M., Liu, D., Feng, L., Zhu, F. X., Tan, X. B., \& Jia, X. B. (2014). Comparison of protective effects of eight ethyl acetate extracts from Eclipta prostrate on NHBE cells based on component structure theory. Zhongguo Zhong Yao Za Zhi, 39(16), 3136-3141.

Feng, H., Wang, Z. M., Dong, G. Y., \& Wu, Z. (2001). Studies on chemical constitutents from Penthorum chinense Pursh. Zhongguo Zhong Yao Za Zhi, 26(4), 260-262. 
Flora of China. (2017). Flora of China. Retrieved from http://www.efloras.org/florataxon. aspx?flora_id=2\&taxon_id=200010148.

Fu, J. J. (2012). Short protocols in medical molecular biology. Beijing, China: China Medical Science Press.

Fu, J., Cheng, J., Liu, X., Li, J., Wei, C., Zheng, X., He, T., \& Fu, J. (2018). Evaluation genotypes of cancer cell lines $\mathrm{HCC} 1954$ and $\mathrm{SiHa}$ by short tandem repeat (STR) analysis and DNA sequencing. Molecular Biology Reports, 45(6), 2689-2695. DOI: 10.1007/ s11033-018-4438-7

Fu, S., Cheng, J., Wei, C., Yang, L., Xiao, X., Zhang, D., Stewart, M. D., \& Fu, J. (2017). Development of diagnostic SCAR markers for genomic DNA amplifications in breast carcinoma by DNA cloning of high-GC RAMP-PCR fragments. Oncotarget, 8(27), 43866-43877. DOI: 10.18632/oncotarget.16704

Fu, J. J., Mei, Z. Q., Tania, M., Yang, L. Q., Cheng, J. L., \& Khan, M. A. (2015). Development of RAPD-SCAR markers for different Ganoderma species authentication by improved RAPD amplification and molecular cloning. Genetics and Molecular Research, 14(2), 5667-5676. DOI: 10.4238/2015.May.25.19

Fu, J., Yang, L., Khan, M. A., \& Mei, Z. (2013). Genetic characterization and authentication of Lonicera japonica Thunb. by using improved RAPD analysis. Molecular Biology Reports, 40(10), 5993-5999. DOI: 10.1007/s11033-013-2703-3

Hu, Y., Wang, S., Wang, A., Lin, L., Chen, M., \& Wang, Y. (2015). Antioxidant and hepatoprotective effect of Penthorum chinense Pursh extract against t-BHPinduced liver damage in L02 cells. Molecules, 20(4), 6443-6453. DOI: 10.3390/molecules20046443

Huang, D., Jiang, Y., Chen, W., Yao, F., Huang, G., \& Sun, L. (2015). Evaluation of hypoglycemic effects of polyphenols and extracts from Penthorum chinense. Journal of Ethnopharmacology, 163(1), 256-263. DOI: $10.1016 /$ j.jep.2015.01.014

Khan, M. A., Cheng, J. L., Mei, Z. Q., Wei, C. L., \& Fu, J. J. (2016). Development of two novel specific SCAR markers by cloning improved RAPD fragments from the medicinal mushroom Ganoderma lucidium (Leysser: Fr) Karst. Genetics and Molecular Research, 15(3), 15038536. DOI: 10.4238/gmr.15038536

Kumla, S., Doolgindachbaporn, S., Sudmoon, R., \& Sattayasai, N. (2012). Genetic variation, population structure and identification of yellow catfish, Mystus nemurus $(\mathrm{C} \& \mathrm{~V})$ in Thailand using RAPD, ISSR and SCAR marker. Molecular Biology Reports, 39(5), 5201-5210. DOI: 10.1007/s11033-011-1317-x.

Lam, K. Y., Chan, G. K., Xin, G. Z., Xu, H., Ku, C. F., Chen, J. P., Yao, P., Lin, H. Q., Dong, T. T., \& Tsim, K. W. (2015). Authentication of Cordyceps sinensis by DNA Analyses: Comparison of ITS Sequence
Analysis and RAPD-Derived Molecular Markers. Molecules, 20(12), 22454-22462. DOI: 10.3390/ molecules201219861

Lee, J. S., Ahn, J. H., Cho, Y. J., Kim, H. Y., Yang, Y. I., Lee, K. T., Jang, D. S., \& Choi, J. H. (2015). $\alpha$-Terthienylmethanol, isolated from Eclipta prostra$t a$, induces apoptosis by generating reactive oxygen species via NADPH oxidase in human endometrial cancer cells. Journal of Ethnopharmacology, 169(1), 426-434. DOI: 10.1016/j.jep.2015.04.029.

Lu, Q., Jiang, M. H., Jiang, J. G., Zhang, R. F., \& Zhang, M. W. (2012). Isolation and identification of compounds from Penthorum chinense Pursh with antioxidant and antihepatocarcinoma properties. Journal of Agricultural and Food Chemistry, 60(44), 11097 11103. DOI: $10.1021 /$ jf303755w

Mei, Z., Zhang, C., Khan, M. A., Zhu, Y., Tania, M., Luo, P., \& Fu, J. (2015a) Efficiency of improved RAPD and ISSR markers in assessing genetic diversity and relationships in Angelica sinensis (Oliv.) Diels varieties of China. Electronic Journal of Biotechnology, 18(2), 96-102. DOI: 10.1016/j.ejbt.2014.12.006

Mei, Z., Zhou, B., Wei, C., Cheng, J., Imani, S., Chen, H., \& Fu, J. (2015b). Genetic Authentication of Gardenia jasminoides Ellis var. grandiflora Nakai by Improved RAPD-Derived DNA Markers. Molecules, 20(11), 20219-20229. DOI: 10.3390/molecules201119687

Mei, Z., Zhang, X., Khan, M. D., Imani, S., Liu, X., Zou, H., Wei, C., \& Fu, J. (2017a). Genetic analysis of Penthorum chinense Pursh. by improved-RAPD and ISSR in China. Electronic Journal of Biotechnology, 30(11), 6-11. DOI: 10.1016/j.ejbt.2017.08.008

Mei, Z., Khan, M. A., Zhang, X., \& Fu, J. (2017b) Rapid and accurate genetic authentication of Penthorum chinense by improved RAPD-derived species-specific SCAR markers. Biodiversitas, 18(3),1243-1249. DOI: $10.13057 /$ biodiv/d180349

Mei, Z., Zhang, X., Liu, X., Imani, S., \& Fu, J. (2017c). Genetic analysis of Canarium album in the different areas of China by improved-RAPD and ISSR. Comptes Rendus Biologies, 340, 558-564. DOI: 10.1016/j. crvi.2017.09.006

Peng, L., Huang, X., Jin, X., Jing, Z., Yang, L., Zhou, Y., Ren, J., \& Zhao, Y. (2017). Wedelolactone, a plant coumarin, prevents vascular smooth muscle cell proliferation and injury-induced neointimal hyperplasia through Akt and AMPK signaling. Experimental Gerontology, 96(1), 73-81. DOI: 10.1016/j. exger.2017.06.011

Pérez, G., Verdejo, V., Gondim-Porto, C., Orlando, J., \& Carú, M. (2014). Designing a SCAR molecular marker for monitoring Trichoderma cf. harzianum in experimental communities. Journal of Zhejiang University. Science B, 15(11), 966-978. DOI: 10.1631/ jzus.B1400063. 
Ryuk, J. A., Kim, Y. S., Lee, H. W., \& Ko, B. S. (2014). Identification of Acorus gramineus, A. calamus, and A. tatarinowii using sequence characterized amplified regions (SCAR) primers for monitoring of Acori graminei rhizoma in Korean markets. International Journal of Clinical and Experimental Medicine, 7(9), 2488-2496.

Wang, H. W., Liu, Y. Q., \& Feng, C. G. (2006). Isolation and identification of a novel flavonoid from Penthorum chinense P. Journal of Asian Natural Products Research, 8(8), 757-761. DOI: 10.1080/10286020500246667

Wang, M., Jiang, Y., Liu, H. L., Chen, X. Q., Wu, X., \& Zhang, D. Y. (2014). A new flavanone from the aerial parts of Penthorum chinense. Natural Product Research, 28(2), 70-73. DOI: 10.1080/14786419.2013.828288

Wang, A., Lin, L., \& Wang, Y. (2015). Traditional Chinese Herbal Medicine Penthorum chinense Pursh: A Phytochemical and Pharmacological Review. The American Journal of Chinese Medicine, 43(4), 601620. DOI: 10.1142/S0192415X15500378

Wang, M., Zhang, X. J., Feng, R., Jiang, Y., Zhang, D. Y., He, C., Li, P., \& Wan, J. B. (2017). Hepatoprotective properties of Penthorum_chinense_Pursh_against carbon tetrachloride-induced acute liver injury in mice. Chinese Medicine, 12(1), 32. DOI: 10.1186/ s13020-017-0153-x
Williams, J. G., Kubelik, A. R., Livak, K. J., Rafalski, J. A., \& Tingey, S. V. (1990). DNA polymorphisms amplified by arbitrary primers are useful as genetic markers. Nucleic Acids Research, 18(22), 6531-6535.

Yang, L., Fu, S., Khan, M. A., Zeng, W., \& Fu, J. (2013). Molecular cloning and development of RAPD-SCAR markers for Dimocarpus longan variety authentication. SpringerPlus, 2(1), 1-8. DOI: 10.1186/2193-1801-2-501

Yang, L., Khan, M. A., Mei, Z., Yang, M., Zhang, T., Wei, C., Yang, W., Zhu, L., Long, Y., \& Fu, J. (2014). Development of RAPD-SCAR markers for Lonicera japonica Thunb. (Caprifolicaceae) variety authentication by improved RAPD and DNA cloning. Revista de Biología Tropical, 62(4), 1649-1657.

Zhang, C., Mei, Z., He, Y., Cheng, J., Khan, M. A., Luo, P., Imani, S., \& Fu, J. (2015). Development of SCAR markers based on improved RAPD amplification fragments and molecular cloning for authentication of three herb medicine Angelica sinensis, Angelica acutiloba and Levisticum officinale. Natural Product Communications, 10(10), 1743-1747.

Zhang, T. T., Xu, X. L., Jiang, M. H., \& Jiang, J. G. (2013). Hepatoprotective function of Penthorum chinense Pursh. Food \& Function, 4(11), 1581-1585. DOI: $10.1039 / \mathrm{c} 3$ fo60245a 